\title{
A VONTADE SEGUNDO JACOTOT E O DESEJO DE CADA UM
}

\author{
Mônica Costa NetTo*
}

\begin{abstract}
RESUMO: Relato circunstanciado da experiência de trabalho com o livro $O$ mestre ignorante, de Jacques Rancière, num curso de formação continuada para educadores de jovens e adultos do estado do Rio de Janeiro no segundo semestre de 2002. A questão da vontade, envolvida no ato de aprendizagem, é abordada a partir das reações dos cursistas aos princípios de uma educação emancipadora, elaborados por Joseph Jacotot (França, século XIX), que são apresentados no livro.
\end{abstract}

Palavras-chave: Vontade. Igualdade. Inteligência. Liberdade. Evasão.

WILL, ACCORDING TO JACOTOT, AND EVERYONE'S DESIRE

ABSTRACT: This paper describes the experience of working with Jacques Ranciere's The ignorant schoolmaster in a continuing education course for adult educators in the State of Rio de Janeiro during the second semester of 2002. The question of the will involved in the act of learning is discussed. It draws from course participants' reactions to the principles of emancipatory education as elaborated by Joseph Jacotot (France, 19th century), which are presented in Ranciere's book.

Key words: Will. Equality. Intelligence. Freedom. Drop-outs.

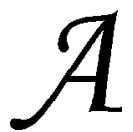

$s$ reflexões que se seguem foram motivadas pela inclusão de $O$ mestre ignorante no programa do Curso de Formação Continuada de Professores de Educação de Jovens e Adultos no Estado do Rio de Janeiro: Cenários em Mudança. ${ }^{1}$ Um exemplar do livro fazia parte do material distribuído gratuitamente aos cursistas, para ser trabalhado no eixo: Ética e cidadania de jovens e adultos em tempos de exclusão, de cuja

* Doutoranda em Filosofia, Université Paris 8. E-mail: mcostanetto@uol.com.br

Educ. Soc., Campinas, vol. 24, n. 82, p. 275-280, abril 2003

Disponível em <http://www.cedes.unicamp.br> 
equipe de professores vim a tomar parte. Devido aos limites de duração do curso, dispúnhamos em nosso programa de apenas algumas horas para a discussão do primeiro capítulo do livro, que os cursistas teriam previamente lido como atividade não-presencial. $\mathrm{Na}$ prática, uma releitura em sala de aula se impunha e as discussōes tendiam a se estender. Para a maioria dos cursistas, o livro trazia uma dificuldade de leitura, parte do vocabulário e sobretudo o desenvolvimento teórico pareciam-lhes difíceis. Mas nem por isso - virtudes do paradoxo? - $O$ mestre ignorante deixava de cativar, instigar, interessar os cursistas. Uma professora chegou a declarar que estava encarando a leitura do livro, com as dificuldades que a ela se apresentavam, como um exercício de emancipação. Este seria um dentre vários exemplos de apropriação, pelos cursistas, das lições do mestre emancipador. Coubeme o prazer de assistir a entrada de Joseph Jacotot em suas vidas:

\section{Na sexta-feira tem pisa na fulô \\ No sábado pela manhã, Jacotot}

Trata-se infelizmente de uma citação infiel, feita de memória, de um poema divertido lido por uma das cursistas ao findar o módulo. $\mathrm{O}$ longo poema, numa alusão aos horários incômodos do curso, dizia em alguns versos que depois do forró da sexta-feira ainda se tinha que acordar cedo para encarar todo um dia de curso no sábado. Fora que rimar "Jacotot" com "fulô" é um achado e tanto, a alusão ao esforço feito pelos cursistas para participarem do curso foi magistralmente "desdramatizada" e, me parece, colocada em termos de uma lógica do desejo. Ir para o forró na sexta-feira $e$ acordar cedo no sábado para ir ao curso são uma conjunção de desejos, não uma alternativa ou disjunção. Talvez implique, a rigor, certo cansaço e desatenção durante o curso. Mas não creio que a conjunção tenha se dado simplesmente porque estar presente, seja em que estado fosse, condicionava a obtenção do certificado do curso. Por um lado, suspeito que tal motivação, em seu modo bruto, não inspire rimas. Por outro, o esforço real de muitos cursistas trazia à tona o questionamento sobre o que queriam os que ali estavam presentes, uma interrogação que não podia deixar de atingir aos mais desatentos. É disso que o poema faz graça. E é possível que a presença de Jacotot, sua situação no poema, a rima formada, também apontem para uma tentativa de resposta ou um prolongamento da questão levantada durante o curso.

O primeiro capítulo do livro, intitulado "Uma aventura intelectual", não se encarrega apenas de apresentar-nos ao curioso personagem que foi Joseph Jacotot e de expor a experiência que deu origem ao seu método de Ensino Universal. O relato histórico dessa experiência insólita 
também nos projeta imediatamente numa reflexão filosófica sobre os princípios surpreendentes a partir dela formulados. Imagine-se, pois, uma turma de professores envolvidos com a educação de jovens e adultos: se muitos são, por experiência própria, receptivos à idéia de que "todo ignorante sabe uma infinidade de coisas", o mesmo já não se dá tão facilmente quando se trata de subverter a "ordem explicadora". Explicar, fazer compreender - preocupações óbvias de um pedagogo esclarecido são, do ponto de vista revolucionário de Jacotot, princípios de uma educação embrutecedora. Uma vez que a explicação pressupõe uma superioridade da inteligência daquele que sabe (o mestre) sobre a inteligência menor, ou menos desenvolvida, daquele que ignora (o aluno). Uma educação emancipadora seria aquela que, invertendo a lógica do sistema explicador, demonstrasse ao aluno que ele é capaz de compreender por si só, pelo poder da sua própria inteligência. E uma tal subversão só é possível a partir de um postulado de base: a igualdade das inteligências. Partindo-se desse princípio, verdadeiro pivô filosófico da descoberta feita por Jacotot, seria possível tornar-se de fato um mestre emancipador.

Muito bem, até aí, seguindo a trajetória da experiência e do pensamento de Jacotot, ainda que abalados pela crítica demolidora do sistema explicativo, os cursistas pareciam acolher sem maiores problemas a novidade dessas idéias, sobretudo relacionando-as aos ensinamentos de Paulo Freire. Mas, eis que na metade do capítulo, a análise da experiência jacotista - que já se revelara um "método do acaso", posto que surgido de uma improvisação, e um "método da igualdade", já que pressupunha a subtração da inteligência explicadora do mestre - encontra um novo termo e se revela como um "método da vontade": "Esse método da igualdade era, antes de mais nada, um método da vontade. Podia-se aprender sozinho, e sem mestre explicador, quando se queria, pela tensão do próprio desejo ou pelas contingências da situação." (Rancière, 2002, p. 30).

Os alunos holandeses de Jacotot haviam aprendido sozinhos o francês que o mestre, ignorando a língua deles, não lhes podia explicar. Sozinhos, sim, sem explicador, mas não sem mestre. Ufa! Estávamos salvos, eu e os professores cursistas, ainda tínhamos uma chance de sobreviver à revolução antipedagógica anunciada nas páginas do livro. A relação entre mestre e aluno envolvendo duas inteligências e duas vontades, uma vez eliminada a subordinação da inteligência do aluno a do mestre, restava ainda uma relação de vontade a vontade, na qual o mestre podia revelar seu valor. Qual seja, manter, pela força da sua vontade, a vontade às vezes vacilante do aluno em seu caminho. Caminho este que não é ditado 
pelo mestre, mas pela marcha da descoberta, pelo aluno, das suas capacidades intelectuais.

Era a essa altura que os cursistas manifestavam-se como se passassem da salvação ao abandono. Ora, desde quando se tinha encontrado a fórmula para despertar o interesse intelectual dos alunos? Como podia parecer assim tão simples sujeitar vontades? Joseph Jacotot devia ser um mestre carismático, dado o seu sucesso em forçar seus alunos a usarem suas próprias inteligências, chegando até a ser capaz de ensinar o que ele mesmo ignorava! Tais reações tinham como pano de fundo o grande problema enfrentado por eles a cada ano: a evasão. Remetidos a uma relação entre vontades, se sentiam desamparados: queremos ensinar, mas quantos querem aprender?

Apesar de Jacotot, estando ali investida dos funestos poderes da explicação, eu tentava fazê-los compreender que a questão da evasão justamente não se enquadrava na ordem das preocupaçôes jacotistas. Erasmo de Roterdã, insurgindo-se contra os maus tratos e castigos corporais infligidos às crianças nas escolas do Renascimento, acreditando apenas na educação praticada dentro de um "espírito liberal”, proclamava a necessidade de escolas públicas, já que a "razão oculta” em favor das sevícias estava no medo da evasão que acarretaria uma diminuição dos lucros. ${ }^{2}$ Sendo o século XIX de Jacotot justamente o da promoção institucional e progressista da instrução pública, seu apego à liberdade na educação viria, por sua vez, a exprimir-se de outra forma: "a instrução é como a liberdade: não se concede, conquista-se” (Rancière, 2002, p. 148). Sendo que a preocupação fundamental de Jacotot não era tanto com a instrução quanto com a emancipação, tarefa que, segundo suas concepções, nenhum governo ou instituição é capaz de realizar. Seu método manifestamente não se destinava aos fins a que se propunham o Ministro da Instrução Pública francês e outros progressistas da época. Por certo, esse método não ia no mesmo sentido dos tantos outros que afloravam então, visando sempre o aperfeiçoamento pedagógico. Isto é, para Jacotot, o refinamento das formas de embrutecimento e da crença na desigualdade. Pois buscar meios de tornar o saber mais acessível ao maior número instruir o povo - é o mesmo que afirmar a sua inferioridade de inteligência. Mas nem por isso deixava de ser um método, inclusive no sentido mais elementar da palavra: um caminho, uma via: a "via da liberdade". Algumas experiências de vulto haviam comprovado a eficácia do método, assim como o fato de que ele podia muito bem prescindir da figura de Jacotot, bastando apenas que aquele que o aplicasse fosse emancipado. Enfim, o "grande lance” do método de Ensino Universal era justamente que ele permitia a 
qualquer um, desde que emancipado, tornar-se um emancipador e, logo, ensinar qualquer coisa. E isso porque, na verdade, só havia uma coisa a ser ensinada: a crença na igualdade das inteligências. Contudo, as experiências também haviam comprovado que o método não resistia à sua captação institucional. Ele não se destinava a educar as massas, mas a revelar a cada um sua natureza de sujeito intelectual.

Há desigualdade nas manifestaçôes da inteligência, segundo a energia mais ou menos grande que a vontade comunica à inteligência para descobrir e combinar relações novas, mas não há hierarquia de capacidade intelectual. É a tomada de consciência dessa igualdade de natureza que se chama emancipação, e que abre o caminho para toda aventura no país do saber. (Rancière, 2002, p. 49)

De um ponto de vista jacotista, poder-se-ia dizer que a evasão é um problema endêmico do ensino embrutecedor. Erasmus pensava que era preciso deixar partir aqueles que por natureza não eram capazes de aprender. "Pois, dizia ele, há homens que nascem para o arado e o moinho tanto quanto os bois ou os asnos" (1529/1991, p. 269). Jacotot, por sua vez, afirmava que não existem asnos ou bois entre os homens, que todo homem, pelo fato mesmo de ser humano, é intelectualmente capaz. Apenas é preciso que se reconheça que em cada manifestação intelectual pode-se encontrar o todo da inteligência humana. Pois uma vez que se foi capaz de aprender alguma coisa, se é sempre capaz de aprender qualquer outra, bastando que se queira, que se encontre uma razão para tanto. Por isso, vontade e razão podem ser considerados sinônimos, são dois nomes para aquilo que faz um sujeito agir, buscar, aprender por si próprio. E a inteligência é antes de mais nada atenção e busca. Todos conhecemos exemplos que demonstram que em dadas circunstâncias, em face de uma necessidade que o constrange, um indivíduo é forçado a superar-se, a sair da impotência do "eu não posso" e alcançar resultados de que não se acreditava capaz. Contudo, nem sempre uma necessidade nos impele a agir, ficamos sozinhos com a nossa vontade e muitas vezes dela nos distraímos, nos ausentamos. E todos temos nossos mais ou menos longos momentos de asnos ou bois: agimos sem vontade, sem reflexão, e assim deixamos adormecer nossas inteligências, não produzimos nenhum ato intelectual.

Ali onde a necessidade cessa, a inteligência repousa, a menos que uma vontade maior se faça ouvir e diga: continua; vê o que fizeste e o que podes fazer se aplicares a mesma inteligência que já empregastes, investindo em toda coisa a mesma atenção, não te deixando distrair em teu caminho. (Rancière, 2002, p. 79) 
Daí a fórmula jacotista: "o homem é uma vontade servida por uma inteligência”. De certa forma isso também significa: "querer é poder". Mas não no sentido de que nada se pode fazer por uma vontade que se desconhece, como se o saber fosse um privilégio dos "fortes". Pelo contrário, o Ensino Universal se destina, sobretudo, àqueles não se conhecem a si mesmos como seres de vontade, capazes não só de desejar, mas de conduzir o próprio desejo. Enfim, se Jacotot havia tido a oportunidade de fazer a experiência inversa da evasão, se ele havia conhecido a "invasão" de seus cursos por alunos interessados em com ele aprender o que o mestre ignorava, me parecia ser antes de mais nada porque, para ele, só existia um tipo de evasão problemática: fugir de si mesmo, deixar-se desviar de seu próprio caminho.

Evidentemente não era possível em tão pouco tempo dar conta do problema. E para todos nós ali, enquanto professores, era grande o desafio de acolhermos o pensamento de Jacotot com toda a sua carga desestabilizadora. De qualquer forma, realmente não era o caso de explicar-lhes o que Jacotot entendia por vontade, mas indicar-lhes que talvez encontrassem as respostas para suas questões nos capítulos seguintes do livro, fazer com que tivessem vontade de prosseguir a leitura sem mim.

Recebido e aprovado em fevereiro de 2003.

\section{Notas}

1. Curso oferecido entre agosto e dezembro de 2002 pelo Laboratório de Políticas Públicas (LPP) da Universidade do Estado do Rio de Janeiro (UERJ) para mais de 2 mil educadores da Rede Pública de Ensino deste estado.

2. "Mas não há nada de grandioso em comandar asnos ou bois, é formar seres livres em liberdade que é ao mesmo tempo muito difícil e muito bonito." (Erasmus, 1529/1991, p. 260).

Referências bibliográficas

ERASMUS. Il faut former les enfants à la vertu et aux lettres dans un esprit libéral... (1529). In: __ . Oeuvres choisies. Paris: Le Livre de poche, 1991.

RANCIÈRE, J. O mestre ignorante: cinco lições sobre a emancipação intelectual. Trad. Lílian do Valle. Belo Horizonte: Autêntica, 2002. (Série: Educação. Experiência e sentido). 